\title{
7 Die Krim als Ort des Frühchristentums
}

\begin{abstract}
Als er hörte, dass die Reliquien des Heiligen Clemens immer noch im Meer lägen, betete er und sagte: „Ich glaube an den Herren und ich hoffe für den Heiligen Clemens, dass ich seine Gebeine finden und sie aus dem Meer bergen kann. “Und er überredete den Erzbischof sowie die Priester und die frommen Leute ein Schiff zu nehmen, und sie segelten zu jenem Ort, wo sich das Meer beruhigte. Dort angekommen, begannen sie zu graben, während sie beteten. Und da verbreitete sich ein starker Duft, wie von einer großen Menge Weihrauch. Und dann zeigten sich die Gebeine, und sie nahmen sie mit großer Ehre und Ruhm. Und all die Priester und Bürger brachten sie in die Stadt. ${ }^{1}$
\end{abstract}

Diese Zeilen stammen aus der bereits zitierten (vgl. Kapitel 2) „Vita des Philosophen Konstantin“, der sich im 9. Jahrhundert auf der Krim aufgehalten haben und ebendort die Reliquien des Clemens Romanus bzw. Clemens von Rom (um 50-97 oder 101) entdeckt und aus den Fluten errettet haben soll. Der als zweiter oder dritter Nachfolger des Apostels Petrus geltende Bischof von Rom erlitt, so heißt es zumindest in der Vita Konstantins, die nicht zuletzt für die Popularisierung dieser Legende sehr entscheidend war, sein Martyrium auf der Krim: Mit einem Anker um den Hals habe er den nassen Tod gefunden, woraufhin an eben dieser Stelle im Meer ein Tempel entstanden sei, in welchem seine Überreste bis zur Errettung durch den Slavenapostel Konstantin einige Jahrhunderte später bewahrt gewesen seien, der sie dann später gemeinsam mit seinem Bruder und Mit-Apostel Methodius dem Papst Hadrian II. (792-872) als Reliquie überantwortet hätte. Diese Reliquien befinden sich heute, zumindest zum Teil - das Kiewer Höhlenkloster nimmt beispielsweise für sich in Anspruch, ebenfalls einige Clemens-Reliquien zu besitzen, u. a. den Kopf des Heiligen - in der Basilika di San Clemente al Laterano in Rom. ${ }^{2}$ Das Martyrium Clemens von Roms auf der Krim im ersten nachchristlichen Jahrhundert wäre, wenn man denn die schon geschilderte Legende des Aufenthalts des Apostels Andreas auf der Halbinsel (vgl. Kapitel 2) in das Reich der Legenden verweist, ein erster Hinweis auf die Berührung der Krim mit dem Christentum. Dabei muss allerdings außer Acht gelassen werden, dass in einigen vorkonstantinischen Quellen von einem natürlichen Tod des Nachfolgers des Petrus ausgegangen wird.

Unbestritten ist, dass die Krim ein Ort des Frühchristentums war, dessen archäologische Spuren sich bis in das beginnende 4. Jahrhundert nachweisen lassen. ${ }^{3}$ Dessen Anfänge hatten sich vermutlich auch in diesem Teil des Schwarzen

1 Žitie (1999), Čtenie 3.

2 Vgl. einführend Schmitt J. (2016).

3 Pillinger (1996), $310 \mathrm{f}$.

๑ OpenAccess. ( 2020 Kerstin S. Jobst, publiziert von De Gruyter. (cc))BY Dieses Werk ist lizenziert unter der Creative Commons Attribution 4.0 International. https://doi.org/10.1515/9783110520620-009 
Meeres in den bereits länger bestehenden jüdischen Gemeinden etwa im Bosporanischen Reich herausgebildet. Die Anwesenheit von ChristInnen auf der Krim ist das Eine, die Herausbildung einer kirchlichen Struktur und Nomenklatura das Andere: Die Teilnahme von Bischöfen von der Krim an dem kirchengeschichtlich so wichtigen Konzil von Nicäa 325 gilt als gesichert. Unklar ist jedoch, um wie viele es sich dabei gehandelt hat. In der Forschung wird diskutiert, ob neben einem Bischof Kadios/Kadmos von Bosporus (Kerč’) auch ein Theophilus von Gotien und ein Chersones vertretender Kirchenmann mit Namen Kapiton anwesend gewesen seien, was ein Beleg für weitere Bischofssitze bereits zur Zeit Konstantins I. („des Großen“, zwischen 270 und 288-337) wäre. ${ }^{4}$ Nicht abschließend geklärt ist, ob von der Existenz eines Chersoneser Bischofssitzes nicht erst um das Jahr $381 \mathrm{zu}$ sprechen ist, als ein Chersoneser Bischof am Konzil von Konstantinopel teilnahm. ${ }^{5}$ Lange Debatten gab es auch darüber, ob es sich bei dem als Teilnehmer am Konzil von Nicäa aufgeführten Theophilus von Gotien tatsächlich um einen Vertreter aus Krim-Gotthia (Doros) gehandelt habe oder ob dieser nicht vielmehr unter den nördlich der unteren Donau siedelnden Terwingen gepredigt habe. Auch wenn sich wohl schon im ausgehenden 3. Jahrhundert ChristInnen unter den BewohnerInnen von Doros befunden haben, so ist ein krimgotischer Bischofssitz in der ersten Hälfte des 4. Jahrhunderts eher unwahrscheinlich. ${ }^{6}$

Unstrittig ist, dass die Krim und vor allen Dingen das unter oströmischer Herrschaft stehende Chersones ein exponierter Verbannungsort insbesondere hoher christlicher Würdenträger gewesen ist. Wie bereits an der oben geschilderten Clemens-Geschichte deutlich wird, ist eine bemerkenswert hohe ,Märtyrerdichte‘ zu verzeichnen, was bereits in den 1920er Jahren den bedeutenden Byzantinisten Vasil'ev darüber sinnieren ließ, ob die Chersoneser Bevölkerung sich dies nicht nur ausgedacht hätte, um ihrer Stadt eine besondere Bedeutung zu verleihen. ${ }^{7}$ In jedem Fall lassen sich aus diesen Befunden zwei Dinge ableiten: Erstens, dass die periphere Lage Chersones' im Gefüge des oströmischen Reiches die Stadt zu einem bevorzugten Verbannungsort machte, und zweitens, dass es erhebliche Spannungen zwischen Konstantinopel und hohen Klerikern gab.

Aus der Reihe echter und vermeintlicher Märtyrer, deren Schicksal sich auf der Krim erfüllte bzw. erfüllt haben soll, sticht Papst Martin I. (um 600-655)

\footnotetext{
4 Vgl. z. B. Vasiliev (1936), 5 f. Referenz ist zumeist Eusebius von Caesarea., Eusebius (2007), u.a. 319.

5 Einführend Plontke-Lüning (2012), 347.

6 Vgl. z. B. Vasiliev (1936), 15, der dies für wahrscheinlich hält. Vgl. auch Schaferdiek (1979), 287289.

7 Vasiliev (1936), 7.
} 
hervor. Der von 649 bis 653 amtierende Papst war mit dem Kaiser in Konstantinopel in Konflikt geraten. Letzterer ließ Martin 653 gewaltsam von Rom nach Konstantinopel verschiffen, foltern und schließlich auf die Krim verbannen, wo dieser wenige Wochen nach seiner Ankunft verstarb. Schnell entwickelte sich in Chersones ein Martins-Kult. ${ }^{8}$ Hintergrund des Chersoneser Exils Martins war das zwischen 537 und 752 dauernde sog. Byzantinische Papsttum, während dessen die Päpste die kaiserliche Zustimmung zu ihrer episkopalen Konsekration benötigten, was dem Herrscher in Konstantinopel eine besondere Machtfülle verlieh.

Während der sog. Ikonoklastischen Krise der Kirche im 8. und 9. Jahrhundert wurden Chersones und die Südküste der Halbinsel schließlich bevorzugter Flucht- bzw. Exilort sowohl bilderfeindlicher als später dann auch bilderfreundlicher Kleriker. ${ }^{9}$ Die lange Zeit in der Forschung vertretene Auffassung, dass gerade die ikonodulen Exilanten die Gebirgszone der Halbinsel mit dem bis heute sichtbaren und beeindruckenden Netz von Höhlenklöstern überzogen hätten, ${ }^{10}$ konnten archäologische Grabungen der letzten Jahrzehnte nicht bestätigen, denn es gibt „für diese Periode keine Belege einer intensiven Bautätigkeit“11; diese müssen also in anderen Zeiten entstanden sein.

Der Südwesten der Krim war folglich in politischer und kulturell-religiöser Hinsicht wesentlich vom Oströmischen Reich und der Orthodoxie beeinflusst, das aus Steppenlandschaften bestehende Hinterland Richtung Festland vergegenwärtigte hingegen weiterhin Einfälle und pragmatische Kooperationen mit nomadischen Völkern aus dem eurasischen Raum.

8 Plontke-Lüning (2012), 348.

9 Gercen u. Mogaričev (1992).

10 Vgl. z. B. Jakobson (1964), 32.

11 Romančuk (2005), 88. 
